\title{
ST-Segment- Elevation Myocardial Infarction for Pharmacoinvasive Strategy or Primary Percutaneous Coronary Intervention in Gaza (STEPP- PCI)
}

\author{
Mohammed Hasirah and Mohammed Habib* \\ Cardiology Department, Alshifa Hospital, Gaza, Palestine
}

*Corresponding author: Mohammed Habib, Cardiology Department, Alshifa Hospital, Gaza, Palestine.

Received Date: : November 04, 2019

Published Date: November 12, 2019

\begin{abstract}
Background: A primary percutaneous coronary intervention (PCI) Primary PCI continues to be the optimal reperfusion therapy in patients with ST elevation myocardial infarction however, in areas where PCI centers are not readily available, a Pharmacoinvasive strategy has been proposed. This study investigated the safety and efficacy of a Pharmacoinvasive strategy compared with primary (PCI) strategy for ST-segment elevation myocardial infarction (STEMI) in Gaza.

Methods: We randomized 145 patients presenting within 2 hours of symptom onset of acute ST elevation myocardial infarction to primary CPI or for pharmaco-invasive PCI 2-24 hours after streptokinase, except in the event of failed reperfusion, in which case, emergency angiography was recommended. The primary endpoint a composite of death, shock and congestive heart failure at 30 days.

Results: Total 145 patients with mean age $56.5+10.48$ years. The primary endpoint in primary PCI (17\%) and in pharmaco-invasive PCI (16.1\%) $\mathrm{p}=0.24$. There was no difference in 30 -day mortality ( $4.7 \%$ in primary PCI and $4.9 \%$ in Pharmacoinvasive strategy $(\mathrm{P}=0.94)$. Secondary endpoints: Emergency angiography was required in $39.5 \%$ of the patients in the pharmaco-invasive strategy and the median time for underwent angiography was 6 hours after randomization. TIMI major bleeding occurred among 4 patients (4.9\%) in the Pharmacoinvasive group and in 2 patients (3.1\%) of the primary PCI group $(\mathrm{P}=0.59)$. The Pharmacoinvasive group had 1.9 times the odds of having TIMI major bleed compared with the primary PCI group
\end{abstract}

Conclusions: A strategy of fibrinolysis with streptokinase in emergency room with early angiography resulted in outcomes similar to primary PCI in patients who undergo PCI within 1 hour after medical contact, however, there was a propensity for more bleeding with a Pharmacoinvasive strategy.

\section{Introduction}

American College of Cardiology/American Heart Association guidelines recommend primary percutaneous coronary intervention (PCI) for patients with ST-segment-elevation myocardial infarction presenting $\leq 12$ hours of symptom onset with a first medical contact-to-device time goal of $\leq 120$ minutes. Pharmacoinvasive strategy where fibrinolysis is followed by immediate transfer to a PCI-capable hospital for either rescue PCI in case of failed fibrinolysis or routine coronary angiography and PCI in case of successful fibrinolysis may be a valid alternative to primary PCI and part of the primary reperfusion in patients with ST-segment-elevation myocardial infarction in whom long PCIrelated delay is anticipated [1]. The aim of our study is to evaluate safety and efficacy of Primary PCI compared to pharmaco-invasive strategy using streptokinase in patients with ST elevation acute myocardial infarction in Gaza.

\section{Methods}

\section{Study design}

This prospective, randomize, case-control study was conducted on 145 patients with first attack of acute STEMI who had symptoms onset of myocardial Ischemia within $12 \mathrm{~h}$ in association with persistent electrocardiographic (ECG) ST elevation and subsequent release of biomarkers of myocardial necrosis.

The subjects were randomly divided (using fixed block randomization) into 2 groups: (Figure 1 ). 


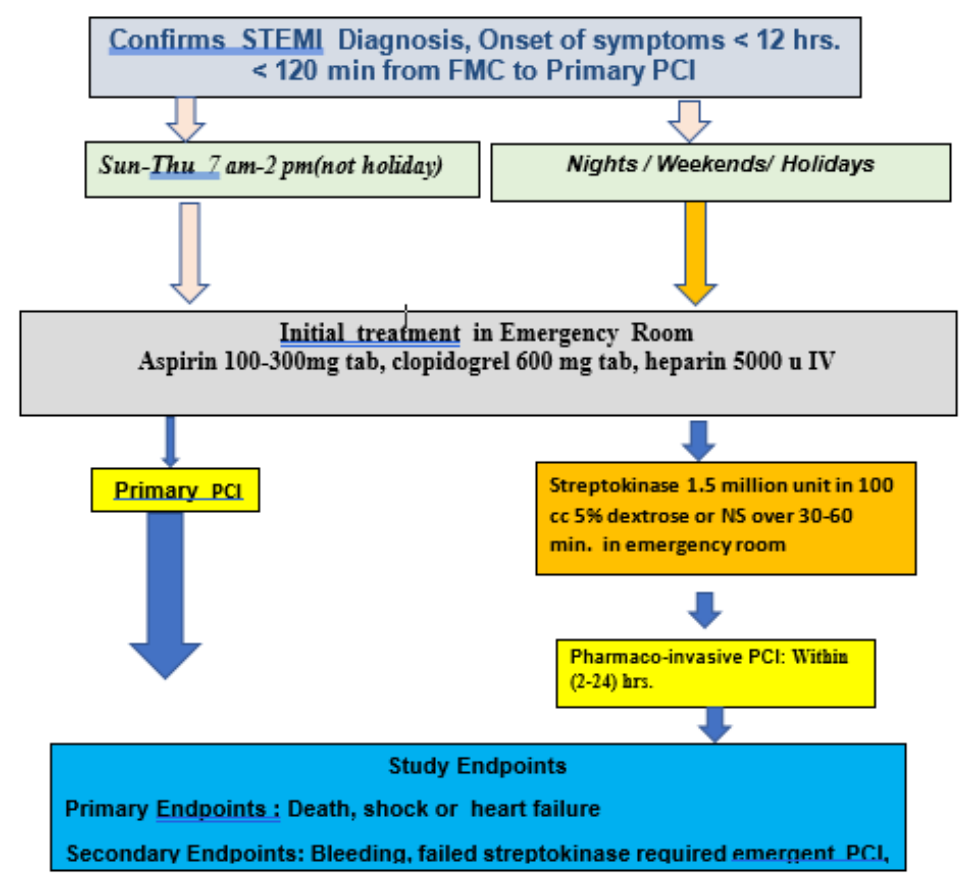

Figure 1: The study flow diagram of patients.

Patients were presents STEMI at the day time between SunThu 7 am-2 pm (not holiday) and patient presents myocardial infarction at night or weekend or holidays who contraindications for streptokinase or cardiogenic shock were randomize to primary PCI, and the patients presents STEMI at Nights or Weekends or Holidays randomize to pharmaco-invasive strategy.

\section{Study populations}

The study population was single Center trial derived from al shifa hospital between January 2019 and October 2012. We identified 145 patients ( $\geq 18$ years) with STEMI $(<12$ hours) eligible for either pharmaco-invasive strategy or Primary PCI. All subjects received acetylsalicylic acid, clopidogrel, unfractionated heparin and high dose statin (Atorvastatin $80 \mathrm{mg}$ ) according to our guidelines. Patients were excluded from the study if their age was $<18$ years or if they have contraindications of fibrinolytic therapy, or multi-vessel coronary artery disease not suitable for revascularization.

\section{Clinical definitions}

STEMI was defined as chest pain suggestive of myocardial ischemia for $\approx 30$ minutes, ST-segment elevation $>0.1 \mathrm{mV}$ in $\geq 2$ contiguous leads, or new or presumably new left bundle-branch block on the 12-lead ECG and elevated cardiac markers (creatine kinase-MB or troponin I/T). PPCI was defined as PCI within 12 hours of symptom onset in a patient not receiving streptokinase. Time to start of reperfusion therapy was defined as time to intravenous injection of fibrinolytics and time to balloon inflation in patients treated with fibrinolysis and PPCI, respectively.

Rescue PCI was defined as PCI mandated by persisting symptoms or persisting ST-segment elevation (failure to achieve $\approx 50 \%$ ST resolution) within 90 minutes after the administration of streptokinase. Pharmacoinvasive strategy was defined as fibrinolysis followed by rescue or by routine elective PCI (beyond 2 hours of fibrinolytic administration). TIMI bleeding classification includes major and minor bleeding. TIMI major bleeding is defined as patients with intracranial hemorrhage or a $>5 \mathrm{~g} / \mathrm{dl}$ decrease in hemoglobin concentration or a $>15 \%$ absolute decrease in hematocrit. If observed with blood loss $>3 \mathrm{~g} / \mathrm{dl}$, decrease in hemoglobin concentration or $>10 \%$ decrease in hematocrit, or no observed blood loss with $>4 \mathrm{~g} /$ decrease in hemoglobin concentration or $>12 \%$ decrease in hematocrit, it is defined as TIMI minor bleeding [2].

\section{End points}

Efficacy (primary) endpoint: total death, shock or heart failure at 30 days after myocardial infarction. Secondary (safety) endpoint: Major Bleeding, minor bleeding or failed streptokinase required emergent PCI.

\section{Statistical analysis}

Data was analyzed by SPSS version 19. Continuous variables were presented as mean \pm standard deviation (SD) and categorical variables as absolute numbers and percentages. Comparison of demographic and clinical data among the groups was performed using independent t-test for continuous variables and chi-square $(\chi 2)$ for categorical variables. Pearson's correlation coefficients were calculated to illustrate certain relationships. P values $<0.05$ were considered significant.

\section{Result}

\section{Baseline characteristics}

Total 145 patient with mean age $56.5 \pm 10.48$ years, The mean age was $55.8 \pm 10.4$ years for the Pharmacoinvasive group 
and $57.5 \pm 10.6$ for the in the primary PCI group. 123 patients (84.8\%) male and 22 patients (15.2\%) were female, 53.1\% were hypertensive, $31.7 \%$ diabetes mellitus, 49.7 smoker,4.8\% previous CABG, $17.2 \%$ previous PCI, 7.6\% COPD, Familial history of CAD $14.7 \%$. (Table 1) baseline characterizes of the patients.

Table 1: Baseline characterizes of the patients.

\begin{tabular}{|c|c|}
\hline & Total (145 patients) \\
\hline Age & $56.5+10.48$ years \\
\hline Sex, male & $123(84.8 \%)$ \\
\hline Diabetes Mellitus & $46(31.7 \%)$ \\
\hline Hypertension & $77(53.1 \%)$ \\
\hline Smoker & $72(49.7 \%)$ \\
\hline Previous CABG & $7(4.8 \%)$ \\
\hline Previous PCI & $25(17.2 \%)$ \\
\hline COPD & $11(7.6 \%)$ \\
\hline Familial history of CAD & $21(14.7 \%)$ \\
\hline
\end{tabular}

\section{Localization of STEMI}

A $75(51.7 \%)$ of study population were presented with anterior STEMI, 58 patients (40\%) with inferior STEMI, 8 patients $(5.5 \%)$ with lateral STEMI and only 4 patients (2.8\%) with posterior STEMI. There was no significant difference among the study groups as regards localization of STEMI.

\section{Type of intervention}

A $64(44.1 \%)$ patients underwent standard primary PCI and 81 (55.9\%) patient underwent Pharmacoinvasive PCI. The Rescue intervention was performed if there was $<50 \%$ STsegment resolution in the single lead of an electrocardiogram or clinical evidence of failed reperfusion within 90 minutes after streptokinase. The rate of rescue PCI was performed in 32 patients (39.5\% of Pharmacoinvasive PCI strategy).

\section{Culprit lesion}

PCI was performed only to the culprit artery. The culprit artery was LAD in 75 patients ( $51.7 \%$ of total study population), LCX in 22 (15\%) patients, RCA in 42 (28\%) patients, OM branch in 6 (4\%) patients and diagonal branch in $2(1.3 \%)$ patient diagonal branch

\section{Door to needle and door to balloon time}

In pharmaco-invasive strategy: Average time from medical contact to streptokinase administration was $33.17 \pm 15 \mathrm{~min}$. in patient with successful streptokinase all Coronary angiography was performed with $24 \mathrm{hrs}$., with average time $16 \mathrm{hrs}$., but in patient with failed streptokinase emergency angiography was required in $39.5 \%$ of the patients the median time 6 hours after randomization. In primary PCI strategy: a $54 \%$ of the patients the Door to balloon time was $<20 \mathrm{~min}$. The Door to balloon time was $75.25 \pm 20 \mathrm{~min}$, and the Door to balloon was performed in $81 \%$ in the time $<90 \mathrm{~min}$.

\section{Endpoints}

Primary endpoint: The primary endpoint in primary PCI $(17 \%)$ and in pharmaco-invasive PCI $(16.1 \%) \mathrm{p}=0.24$. There was no difference in 30-day mortality ( $4.7 \%$ in primary PCI and
4.9\% in Pharmacoinvasive strategy $(\mathrm{P}=0.94)$ Secondary endpoints: Emergency angiography was required in $39.5 \%$ of the patients in the pharmaco-invasive strategy and the median time for underwent angiography was 6 hours after randomization. TIMI major bleeding occurred among 4 patients (4.9\%) in the Pharmacoinvasive group and in 2 patients $(3.1 \%)$ of the primary $\mathrm{PCI}$ group $(\mathrm{P}=0.59)$. The Pharmacoinvasive group had 1.9 times the odds of having TIMI major bleed compared with the primary PCI group (Table 2).

Table 2: Baseline characterizes of the patients.

\begin{tabular}{|c|c|c|c|}
\hline & Primary PCI & $\begin{array}{c}\text { Pharmaco- } \\
\text { invasive PCI }\end{array}$ & P value \\
\hline $\begin{array}{c}\text { Primary end point: } \\
\text { Total mortality, Shock } \\
\text { or heart failure }\end{array}$ & $11(17 \%)$ & $13(16.1 \%)$ & 0.24 \\
\hline Total mortality & $3(4.6 \% 0$ & $4(4.9 \%)$ & 0.94 \\
\hline Shock & $3(4.6 \%)$ & $7(8.6 \%)$ & 0.35 \\
\hline heart failure & $10(15.6 \%)$ & $15(18.5 \%)$ & 0.62 \\
\hline Secondary endpoint: & $2(3.1 \%)$ & $4(4.9 \%)$ & 0.59 \\
\hline Major bleeding & $3(4.6 \%)$ & $8(9.8 \%)$ & 0.24 \\
\hline Minor bleeding & - & $32(39.5 \%)$ & \\
\hline Rescue PCI & & & \\
\hline
\end{tabular}

\section{TIMI flow before and after PCI}

There were heavier thrombus burden and lower pre-PCI TIMI flow (TIMI-0 and TIMI-I) in patients within primary PCI (79\%) compared to Pharmacoinvasive PCI (23\%) (P value 0.001). PostPCI TIMI flow was improved in all study groups with no significant differences among them (P value 0.1). Thrombus aspiration was done in only 2 (1.3\%) patients while GP IIb/IIIa inhibitors were needed in 14 (9.6\%) patients.

\section{Subgroup Analysis}

In the Pharmacoinvasive group, 32 patients did receive coronary angiography within 6 hours and 57 patients was receive coronary angiography within 24 hours of presentation; 5 underwent angiography later during the index hospitalization and 3 were treated medically (two patients ecstatic coronary arteries and slow flow another patient was nonsignificant stenosis). Three patients died within $48 \mathrm{~h}$ of presentation, and 1 patient died later on due to subacute stent thrombosis.

In the primary PCI group, 1 patient died just before reaching the catheterization laboratory, Cardiopulmonary resuscitation and primary PCI was done but patient died in the table of cardiac catheterization, 2 patients within 24 h of presentation. The results of the our analysis including only patients who underwent coronary angiogram and PCI within $24 \mathrm{~h}$.

\section{Discussion}

In our trial, we report on the efficacy and safety of a Pharmacoinvasive strategy compared with a primary PCI strategy in Gaza, we found that:

1. First, Streptokinase: It is a very widely used fibrinolytic agent and only available fibrinolytic agent in Gaza, because of its easy availability and low cost. 
2. Second, Actually, it has to be considered that patients enrolled in our trial were at low risk with a 30-day mortality of $4.8 \%$.

3. Third, the rate of composite end points (total mortality, shock and heart failure) was similar in two groups.

4. Forth, a $39.5 \%$ of patients in the thrombolysis arm required urgent coronary angiography.

5. Fifth, major bleeding was slightly lower with a primary PCI strategy

Our primary endpoints was similar with The STREAM (Strategic Reperfusion Early After Myocardial Infarction) trial compared fibrinolysis followed by PCI within 6 to $24 \mathrm{~h}$ to primary PCI. The investigators found that there was no difference in the composite end point of death, shock, congestive heart failure, or reinfarction at 30 days between the 2 treatments [2] However, a fibrinolysis-based therapy was associated with slightly higher rates of intracranial hemorrhage, a trend that was not observed after protocol amendment to reduce TNK by $50 \%$ for patients $>75$ years of age, in our trial we use streptokinase and number of patients who had age $>75$ years only 8 patients and 5 of them was randomize to primary PCI strategy [3]. Within this regional STEMI system, $>50 \%$ of the patients managed with a Pharmacoinvasive strategy underwent PCI within $260 \mathrm{~min}$ ( $4 \mathrm{~h}$ and $20 \mathrm{~min}$ ) from the time of receiving fibrinolytic therapy. In randomized controlled trials looking at a Pharmacoinvasive strategy, the median time from fibrinolysis to PCI was $84 \mathrm{~min}$ in CAPITAL-AMI (Combined angioplasty and pharmacological intervention versus thrombolysis alone in acute myocardial infarction), 125 min in CARESS-in-AMI (Combined Abciximab REteplase Stent Study in Acute Myocardial Infarction), 163 min in NORDISTEMI (NORwegian study on District treatment of ST-elevation myocardial infarction) and $234 \mathrm{~min}$ in TRANSFERAMI (Trial of Routine Angioplasty and Stenting After Fibrinolysis to Enhance Reperfusion in Acute Myocardial Infarction) [4-8]

In a large meta-analysis of 7 trials and 2,961 patients, early PCI after fibrinolysis has been found to be associated with a reduced risk of the combined endpoint of death and reinfarction without a significant increase in the risk of major bleeding or stroke [9]. The our result is similar to the STEPP-AMI, trial which a prospective, observational, multicentric study evaluated the efficacy and safety of a strategy of pharmaco-invasive therapy with primary PCI. In this study, tenecteplase was given as the lytic agent followed by catheterization (pharmaco-invasive strategy) within 3-24 hours with timely coronary intervention as appropriate versus standard primary PCI in 200 patients with acute myocardial infarction within 12 hours of symptom onset. The primary endpoint of 30day incidence of death, cardiogenic shock, reinfarction, repeat revascularization, and congestive heart failure, was similar in both groups, although there was a trend toward benefit in the primary PCI group (11.1\% vs. 3.9\%, p = 0.07). At the end of 2-year followup, the initial benefit from primary PCI seemed to be narrowed as more events have occurred in the primary PCI group vs pharmaco- invasive group (17.8\% vs. $13.6 \%, p=0.47)$ [10] Limitations The limitations in this study were the small sample size, short term 30 days of follow-up.

\section{Conclusion}

In this randomized trial, early presenting STEMI patients unable to undergo primary PCI within 1 hour (median, $75 \pm 20$ minutes) were randomized to primary PCI or a pharmaco-invasive strategy with streptokinase followed by PCI. At 1-month followup, there was no statistical difference in all-cause mortality, heart failure or shock. This study suggests that, if primary PCI cannot be performed within 1 hour of presentation, a pharmaco-invasive strategy may be as good as primary PCI.

\section{Acknowledgements}

None.

\section{Conflict of Interest}

No potential conflict of interest relevant to this article was reported.

\section{Study Association}

This article is part of the Cardiology Board thesis. Palestinian Cardiology Board -AL Shifa Hospital - Gaza - Palestine.

\section{References}

1. O'Gara PT, Kushner FG, Ascheim DD, Casey DE, Chung MK, et al. (2013) ACCF/AHA guideline for the management of STelevation myocardial infarction: a report of the American College of Cardiology Foundation/ American Heart Association Task Force on Practice Guidelines. J Am Coll Cardiol 127(4): e362-e425.

2. Chesebro JH, Knatterud G, Roberts R, Borer J, Cohen LS, et al. (1987) Throm-bolysisinmyocardialinfarction (TIMI) trial, phaseI: a com-parison between intravenous tissue plasminogen activator andintravenous streptokinase. Clinical findings through hospitaldischarge. Circulation 76(1): 142-154

3. Armstrong PW, Gershlick AH, Goldstein P, Wilcox R, Danays T, et al. (2013) Fibrinolysis or primary PCI in ST-segment elevation myocardial infarction. N Engl J Med 368: 1379-1387.

4. Le May MR, Wells GA, Labinaz M, Davies RF, Turek M, et al. (2005) Combined angioplasty and pharmacological intervention versus thrombolysis alone in acute myocardial infarction (CAPITAL AMI study). J Am Coll Cardiol 46: 417-424.

5. Di Mario C, Dudek D, Piscione F, Mielecki W, Savonitto S, et al. (2008) Immediate angioplasty versus standard therapy with rescue angioplasty after thrombolysis in the Combined Abciximab REteplase Stent Study in Acute Myocardial Infarction (CARESS-in-AMI): an open, prospective, randomised, multicentre trial. Lancet 371: 559-568.

6. Bøhmer E, Hoffmann P, Abdelnoor M, Arnesen H, Halvorsen S, et al. (2010) Efficacy and safety of immediate angioplasty versus ischemiaguided management after thrombolysis in acute myocardial infarction in areas with very long transfer distances results of the NORDISTEMI (NORwegian study on DIstrict treatment of ST-elevation myocardial infarction). J Am Coll Cardiol 55 (2): 102-110.

7. Lavi S, Cantor WJ, Casanova A, Tan MK, Yan AT, et al. (2012) Efficacy and safety of enoxaparin compared with unfractionated heparin in the pharmacoinvasive management of acute ST-segment elevation myocardial infarction: Insights from the TRANSFER-AMI trial. Am Heart J 163 (2): 176-81.e2.

8. Fernández-Avilés F, Alonso JJ, Peña G, Blanco J, Alonso-Briales J, et al. (2007) Primary angioplasty vs. early routine post-fibrinolysis angioplasty for acute myocardial infarction with ST-segment elevation: 
the GRACIA-2 non-inferiority, randomized, controlled trial. Eur Heart J 28 (8): 949-960.

9. Borgia F, Goodman SG, Halvorsen S, Cantor WJ, Piscione F, et al. (2010) Early routine percutaneous coronary intervention after fibrinolysis vs. standard therapy in STsegment elevation myocardial infarction: a metaanalysis. Eur Heart J 31: 2156-2169.
10. Antoniades L, Christodoulides T, Georgiou P, Hadjilouca C, Christodoulou E, et al. (2014) Epidemiology of acute coronary syndromes in the Mediterranean island of Cyprus (CYPACS study, Cyprus study of acute coronary syndromes). Hellenic J Cardiol 55: 139-149. 